\title{
Connecting Cognitive and Behavioral Characteristics of Policy Conflict in Oil and Gas Politics
}

Christopher M. Weible and Tanya Heikkila

\section{(2) OpenEdition Journals}

Electronic version

URL: https://journals.openedition.org/irpp/1312

DOI: 10.4000/irpp.1312

ISSN: 2706-6274

\section{Publisher}

International Public Policy Association

\section{Printed version}

Date of publication: 15 December 2020

Number of pages: 245-263

ISSN: 2679-3873

\section{Electronic reference}

Christopher M. Weible and Tanya Heikkila, "Connecting Cognitive and Behavioral Characteristics of Policy Conflict in Oil and Gas Politics", International Review of Public Policy [Online], 2:3 | 2020, Online since 15 December 2020, connection on 08 September 2021. URL: http://journals.openedition.org/ irpp/1312 ; DOI: https://doi.org/10.4000/irpp.1312

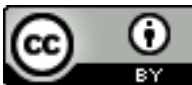

International Review of Public Policy is licensed under a Creative Commons Attribution 4.0 International. 


\section{Connecting Cognitive and Behavioral Characteristics of Policy Conflict in Oil and Gas Politics}

\section{Christopher M. Weible}

School of Public Affairs, University of Colorado Denver

\section{Tanya Heikkila}

School of Public Affairs, University of Colorado Denver

\section{Abstract}

The essence of policy conflicts remains largely underdeveloped, both theoretically and empirically. We explore policy conflict and explain its cognitive and behavioral characteristics using data from a survey administered to policy actors involved in oil and gas politics in Colorado, USA. The analysis begins with a description of the cognitive and behavioral characteristics of policy actors and then combines them into a single index to depict varying intensities of conflict. Cognitive characteristics are comprised of three dimensions: disagreement on public policy, perceived threats from opponents, and an unwillingness to compromise. Behavioral characteristics include engagement by policy actors in a range of activities, from mobilizing opponents to providing information to the media. Ordered Logit models are used to associate the attributes of policy actors with cognitive and behavioral characteristics and an index of conflict intensity that combines these two characteristics. The conclusion offers questions and recommendations for future research.

\section{Keywords}

fracking, energy politics, policy processes, public policy, contentious policy 


\section{Introduction}

Conflicts over policy decisions - or what government should or should not do - pervade phenomena relating to politics and government. Policy conflicts bring to light competing interests and values in society and, in doing so, can be both productive and destructive to political systems. Moderate levels of conflict, for instance, may lead to innovative policy decisions and learning. More intense levels of conflict, however, may reflect an inability of policy actors to compromise, an entrenchment of beliefs, or a demonization of opponents. Despite the importance of policy conflict to society and to policy processes, policy scholars often neglect to describe and explain the underlying characteristics of policy conflicts. To help address this limitation, we offer theoretical and empirical insights into policy conflicts by examining the cognitive and behavioral characteristics of the policy actors involved.

The Policy Conflict Framework (PCF) helps guide our analysis (Heikkila \& Weible, 2017; Weible \& Heikkila, 2017). Under the PCF, a policy conflict occurs when two or more policy actors exhibit varying levels of certain cognitive and/or behavioral characteristics around a proposed or existing policy decision or action. The cognitive characteristics of policy conflict consist of disagreement on policy proposals between policy actors, perceived threats that policy actors feel from their opponents' policy proposals, and an unwillingness to compromise by one or more policy actor. The behavioral characteristics of policy conflict include the actions that policy actors deploy to influence the policy decision. To date, the empirical research has yet to explore the cognitive and behavioral dimensions of a policy conflict in tandem, an exploration which would aid understanding of the intensity of policy conflict and, eventually, comparisons of policy conflict.

We apply PCF as a lens to study policy conflict surrounding oil and gas development in the state of Colorado, which, like many regions of the United States, has witnessed significant growth in oil and gas drilling over the last decade. Hydraulic fracturing and horizontal drilling technologies have spurred the expansion of oil and gas development in Colorado. Many properties, towns, and cities have been exposed to the industry in ways never experienced before. Additionally, as we have seen at both the national level, and across other states, disagreements about the risks and benefits of oil and gas development are prevalent in Colorado (Weible \& Heikkila, 2016; Heikkila, Weible, \& Olofsson, 2017). As Colorado is representative of the types of issues surrounding debates over unconventional oil and gas development, it offers a useful case for probing new theoretical insights around policy conflict.

This article explores the cognitive and behavioral characteristics of policy conflict, how they relate to each other, and what factors shape them among a population of policy actors involved in oil and gas politics in Colorado. Before presenting the methods and results, we offer a synopsis of the PCF and the oil and gas case study in Colorado. This article concludes with an examination of the theoretical and empirical insights that this research offers the literature and some lessons for how we conceive of, and assess, policy conflicts.

\section{A Synopsis of the Policy Conflict Framework}

One assumption of the research conducted in this article is that the deliberate use of an analytical lens, in the form of a framework, helps to clarify concepts and their interdependencies in the study of a phenomenon. The lens used to help in guiding this case is the PCF, which was created to bring theoretical and empirical attention to one of the most important concepts in the study of policy and politics: conflict (Weible \& Heikkila, 2017). The PCF operates as a bri- 
colage of different theoretical and methodological insights from various literatures which are related to, and which can inform, policy conflicts. These include Schattschneider $(1957 ; 1960)$, the Advocacy Coalition Framework (Jenkins-Smith et al., 2017), the Institutional Analysis and Development Framework (Ostrom, 2009), the conflict-resolution and alternative dispute literatures (Susskind et al., 1999), and political psychology (Kahan, 2012; Kahneman \& Tversky, 2013). Building on these forms of knowledge, the PCF represents a reservoir of insights that can guide research in studying the sources, characteristics, and effects of policy conflicts, the evolution and change of policy conflicts over time, and the comparisons of policy conflicts across settings.

What is policy conflict? The answer depends on the scale of the research (individual, policyaction situation, policy subsystem, political system), the intent of the researcher and the researcher's questions. For this study, we explore policy conflict within a policy subsystem (oil and gas development) and tie the meaning of policy conflict to a population of policy actors who are individuals in and outside of governments engaged in the subsystem. The manifestation of conflict within this subsystem can be observed through the cognitive and behavioral characteristics of conflict within and among policy actors. This means that we depict policy conflict based on the ways in which people perceive conflict and exhibit conflict behaviors in relation to the issue in a policy subsystem. We make no judgments in this article, and neither does the PCF, about whether characteristics of policy conflict in this study are good or bad for policy outcomes or for democratic institutions. In this regard, our objectives are normatively agnostic and focused on descriptive and explanatory objectives.

The PCF operationalizes individual-level cognitive and behavioral characteristics of policy conflict through their underlying dimensions. The first dimension that underlies cognitive characteristics is the divergence between policy actors' policy proposals or positions. This first dimension reflects a number of similar depictions of conflict and contention as deriving from differences in public policy positions (Tilly \& Tarrow, 2007; Jenkins-Smith et al., 2014). The second cognitive dimension involves threats from opponents' policy positions. Divergence in positions alone is not always conflictual; conflicts emerge when the position of one policy actor is perceived as a threat to another (Tilly \& Tarrow, 2007; Cobb \& Elder, 1972; Jenkins-Smith et al., 2014). The third cognitive dimension is an unwillingness to compromise by policy actors on policy positions, which sustains conflict. The minimum conditions for policy conflict to be present among a group of policy actors require at least two or more individuals to exhibit these three characteristics. However, we also recognize that there may be varying levels or degrees of these characteristics present within a group of policy actors. For instance, there may be more or less intensity, both in the number of actors and in the perceptions of actors who express divergence in positions, perceived threats, or unwillingness to compromise.

The behavioral characteristics of conflict involve a range of strategies or tactics used by policy actors to influence different aspects of government policies. Hundreds of such behaviors might exist, but for simplification, one way to categorize them includes considering "inside" government activities, or those that attempt to influence government officials directly. This might involve communicating with government officials by providing information through various means (e.g. letters, lobbying, reports), or sharing opinions with government officials in different types of government decision-making processes (Schattschneider, 1960; Baumgartner \& Jones, 1993; Pralle, 2006). Other behaviors include "outside" government activities, such as mobilizing the general public, building and maintaining advocacy coalitions, or running media campaigns. Although one might assume that behavioral characteristics might be adversarial 
(e.g. coordinating only with allies), they can also be collaborative (e.g., cooperating with opponents, or brokering agreements among parties during policy conflict) (Jenkins-Smith, 1990; Weible, 2008). As with cognitive characteristics, at least two or more policy actors would exhibit behavioral characteristics of conflict when policy conflict exists, and the degree to which different policy actors engage in these behaviors will vary within political systems, policy subsystems, or policy action situations.

The cognitive and behavioral characteristics of conflict can be unpacked for analysis of their underlying dimensions, or they can be combined into an index for the analysis of policy conflict between policy actors at different levels of analysis (Heikkila \& Weible, 2017). In this article, we use two sets of survey questions to create indices of the cognitive and behavioral characteristics of policy conflict: one that combines the three cognitive dimensions and another that combines multiple behavioral dimensions. We then combine these two indices into a cognitive and behavioral composite index. As explained later in this article, we use an ordered logit model to specify the various likelihoods of policy actors falling along the spectrum of cognitive and behavioral (or combined) characteristics, based on their intrapersonal (e.g., what they perceive or know) or their interpersonal (e.g., how they relate to others) attributes.

\section{Hypotheses}

Under the logic of the PCF, theoretical relationships among key factors in policy conflicts are expressed through a set of "primary dynamics" which embody the general theoretical expectations of the PCF (Weible \& Heikkila, 2017). The logic of the primary dynamics offers a foundation for deriving contextually specific hypotheses for one or more case studies. We expect some hypotheses to be confirmed and others to be refuted, depending on the types of measures and the particularities of the case. Over time, and through the testing of hypotheses across multiple cases, the primary dynamics of policy conflicts will be updated and revised.

The two defining characteristics of policy conflicts under the PCF are expected to be interactive and related. However, the direction of their relationship is difficult to ascertain a priori. One might assume that cognitive characteristics of policy conflict should precede the behavioral characteristics of policy conflict. The temporal assumption here is that people think before they act and that no action precedes those thoughts. In policy conflicts, such as oil and gas politics in Colorado, policy actors are likely to have experienced conflict cognitively and behaviorally. Memories and experiences of past actions may heighten or dampen current perceptions of conflict. The relationships between cognition and behavior are therefore likely to be dynamic and difficult to tease apart in any research study, particularly cross-sectional surveys as used herein. Thus, in this study, we do not posit a one-directional relationship to and from the two characteristics of policy conflict. Instead, we expect the cognitive characteristics and behavioral characteristics of policy conflict to be associated. While this hypothesis might be indisputable, it has yet to be formally written and tested and the nature of the posited association is very much unknown; that is, it could be linear or nonlinear. We therefore treat this first hypothesis as a relationship possibly to confirm, but more as a means to focus attention on, the nature of the association, assuming that there is one. It is possible that this relationship is not a given. For instance, some individuals might express cognitive characteristics of conflict, but do not engage in conflictual behaviors. It may also be possible that policy actors exhibit conflictual behaviors, for instance as part of their professional duties, but they may not manifest high levels of the cognitive characteristics of conflict. 
In addition to identifying the underlying characteristics of policy conflict, the PCF posits that the intrapersonal and interpersonal attributes of policy actors shape policy conflicts, recognizing that how these attributes play out within particular policy conflicts is likely to vary. These attributes may also vary depending on whether we focus on the cognitive or behavioral characteristics of conflict, or on the combination of these characteristics. In previous research we have examined how these attributes relate to cognitive characteristics (Heikkila \& Weible, 2017), but we have not explored whether these relationships hold when considering behavioral characteristics and the combination of cognitive and behavioral characteristics.

The intrapersonal attributes examined include deep core beliefs, policy-relevant knowledge, and perceptions of risks and benefits. We operationalize deep core beliefs based on the Advocacy Coalition Framework (Jenkins-Smith et al,. 2014). Deep core beliefs are fundamental normative or ontological orientations. We operationalize deep core beliefs via a traditional right-left measure of political ideology. Previous research found that more liberal political ideology was associated with greater odds of scoring higher on the cognitive index of policy conflict in the case of oil and gas development (Heikkila \& Weible, 2017). This relationship could play out similarly with behavioral characteristics, but we do not have a priori theory to develop this expectation. Therefore, we simply expect that political ideology will be associated with policy conflict characteristics.

The second intrapersonal attribute is policy-relevant knowledge that captures policy actors' experience and expertise in relation to the policy issue. Policy-relevant knowledge is important in policy conflict, in part because it can be associated with cognitive biases and sources of disagreement (Jenkins-Smith, 1990; Weible, 2008). It can also provide the capacity that policy actors need to engage in policy conflict behaviors and, thus, represents a form of power. The measure used in this study for policy-relevant knowledge includes diversity of experience with oil and gas issues and formal education. Prior research found that education played a minor role in shaping cognitive characteristics of conflict (namely, higher levels of education were significantly associated with lower odds of divergent policy positions, but not with the composite cognitive conflict index). We expect that, when behavioral characteristics are accounted for, policy relevant knowledge will be associated with policy conflict characteristics.

As the third intrapersonal policy actor attribute, perceptions of risks and benefits relate to the relative tradeoffs involving perceived losses and harms from an issue versus the perceived gains. Perceptions under the PCF are identified, filtered, and processed through their beliefs, emotions, and identities. This article provides two measures of risks and benefits: 1 ) the perceived relative balance of risks and benefits; and 2) the perceived rigidity of risk and benefit perceptions. Past research on the cognitive characteristics of policy conflict found that the rigidity of risk-benefit perceptions was consistently associated with cognitive characteristics, but perceiving more risks relative to benefits was not (Heikkila \& Weible, 2017). When accounting for behavioral characteristics, we do not know if this pattern will hold. Rigidity may be more important in shaping cognitive outcomes, while higher risk perceptions may lead policy actors to engage in more behaviors, or both. Therefore, we hypothesize that policy actors who perceive more risks relative to benefits, and the more rigidity there is in risk-benefit perceptions, the more policy actors are likely to exhibit intense policy conflict characteristics.

This article uses two concepts and measures of interpersonal attributes to help understand policy conflicts. For the first, we assess the extent that policy actors are isolated in their networks. As past research on cognitive characteristics has shown, the more isolated policy actors are, the more constrained are their sources of information, the more closed are their perspec- 
tives and the more they are likely to exhibit intense cognitive conflict characteristics (Heikkila \& Weible, 2017). Recognizing that insulated networks may affect behaviors in a different way than cognitive characteristics, in general, we hypothesize that policy actors with more insulated policy actor networks are more likely to exhibit intense policy conflict characteristics.

For the second interpersonal attribute, this article includes measures of organizational affiliation. Drawing on lessons from the Advocacy Coalition Framework (Jenkins-Smith, et al., 1991), we expect non-government organizations to experience conflict in a different way than government organizations, especially in their roles as advocates. This was the case with findings of cognitive characteristics of conflict in the oil and gas subsystem (Heikkila \& Weible 2017); we would logically assume this finding to hold when accounting for behaviors. Thus, we hypothesize that individuals affiliated with organizations that have taken advocacy positions (e.g. environmental groups or industry associations) are more likely to exhibit intense policy conflict characteristics than are non-advocacy oriented organizational affiliations (e.g. government and academia).

\section{Study Context}

The level of action for this application of the PCF is the policy subsystem relating to oil and gas development using hydraulic fracturing in Colorado. Between 2007 and 2013, crude oil production in Colorado rose by $146 \%$ and natural gas production rose by $38 \%$, making Colorado one of the largest producers of energy from oil and natural gas in the United States (U.S. Energy Information Administration 2014a). Most of the gas and oil development since 2007 has occurred in the Denver-Julesberg Basin in north-east Colorado (U.S. Energy Information Administration, 2014b), which is close to Colorado's major metropolitan areas. At the time that the data were collected for this study, shale oil and gas production were at peak levels in Colorado (Hood 2016).

In response to this growing industrial activity, local advocacy groups have formed to protest industry proposals to drill new oil and gas wells within their communities. Some local communities have tried to ban or impose moratoria on hydraulic fracturing as well. The state has adopted several regulatory changes in response to concerns over oil and gas development, such as mandatory requirements for disclosure of hydraulic fracturing chemicals, increased setback distances between wells and occupied buildings, floodplain mapping requirements, and rules for controlling methane and other air pollutants in the production process. Additionally, a Governor's Task Force was formed in 2014 as a way to mitigate disputes between pro- and anti- oil and gas groups. The Task Force produced state-level policy recommendations in 2015 regarding the allocation of authority in governing hydraulic fracturing between local and state levels. Disputes over jurisdictional issues have also been expressed in state courts. For example, the oil and gas industry sued local governments that tried to ban fracking in 2014 and, in 2016, the Colorado Supreme Court ruled that local-level hydraulic fracturing bans violated the pre-emption clause of the state constitution.

\section{Data and Methods}

In studying the subsystem-level conflict around oil and gas development in Colorado, we first conducted nine interviews with policy actors from diverse backgrounds, so as to provide information on the research context. We then administered an email survey through Qualtrics, an online survey platform. The survey population included 453 individuals actively involved or knowledgeable about oil and gas development in Colorado. These individuals were identified 
using a purposive sampling approach based on evidence in media reports, online reports, public hearings and testimony, and on recommendations from interviewees. ${ }^{1} \mathrm{~A}$ total of 213 people responded to the survey, yielding a $47 \%$ response rate. ${ }^{2}$ Not all respondents chose to answer every question, so the response rates vary by question. Consistent with PCF, the survey questions were designed to capture dimensions of the characteristics of policy conflicts, attributes of the policy setting, and effects of conflicts. ${ }^{3}$

This article creates three indices to operationalize the concept of policy conflict. Table 1 shows the measures and calculations for the two indices for the cognitive and behavioral characteristics of policy conflict and the composite index that combines them. All three indices rely on the 2015 survey data.

Table 1. Operationalization of the Characteristics of Policy Conflict

\begin{tabular}{|l|l|l|}
\hline $\begin{array}{l}\text { Cognitive } \\
\text { Characteristics }\end{array}$ & Operational Measure & Calculations \\
\hline $\begin{array}{l}\text { Divergent } \\
\text { Policy Positions }\end{array}$ & $\begin{array}{l}\text { "What comes closest to your current policy posi- } \\
\text { tion on oil and gas development that uses hydrau- } \\
\text { lic fracturing: stop, limit, continue at the current } \\
\text { rate, expand moderately, or expand extensively } \\
\text { (1= stop; 5= expand extensively)" }\end{array}$ & $\begin{array}{l}\text { Subtracted the } \\
\text { mean score of this } \\
\text { scale (2.96) from } \\
\text { each respondent's } \\
\text { position score and } \\
\text { took the absolute } \\
\text { value }\end{array}$ \\
\hline $\begin{array}{l}\text { Perceived } \\
\text { Threats from } \\
\begin{array}{l}\text { Opponents" } \\
\text { Policy }\end{array}\end{array}$ & $\begin{array}{l}\text { "To what extent do the views and actions of those } \\
\text { you disagree with on oil and gas development us- } \\
\text { ally or professionally; and (b) threaten Colorado?" } \\
\text { Both response categories were on a scale of 1-5 } \\
\text { (1= not at all; 5=a great deal). }\end{array}$ & $\begin{array}{l}\text { Added the values of } \\
\text { these two catego- } \\
\text { ries for a combined } \\
\text { threats" } \\
\text { for score } \\
\text { eal individ- } \\
\text { (ranging from } \\
2-10)\end{array}$ \\
\hline
\end{tabular}

1 - The initial target list of respondents was 630 individuals. After eliminating bounced emails from the list and individuals who were not actively involved in the issue, the final population was 453.

2 - The response rates by organizational affiliation are: local government ( 60 of $127=47 \%$ response rate); industry (51 of $123=41 \%$ ); environmental non-profits (31 of $61=51 \%$ ); state government ( 21 of $28=75 \%$ ); legal professionals (17 of $34=50 \%$ ); organized citizen groups (9 of $18=50 \%$ ); university/consultants (12 of $30=40 \%$ ); industry nonprofits ( 6 of $12=50 \%$ ); other non-profits ( 5 of $9=56 \%)$; media ( 1 of $6=17 \%)$, federal government $(0$ of $4=0 \%)$; and "other" (0 of $1=0 \%)$.

3 - Access to the full survey instrument can be found at Heikkila \& Weible (2015). 


\begin{tabular}{|c|c|c|}
\hline $\begin{array}{l}\text { Unwillingness to } \\
\text { Compromise }\end{array}$ & $\begin{array}{l}\text { Respondents were asked "limit" and "expand" } \\
\text { questions: } \\
\text { "(1) Would you support government decisions } \\
\text { that would significantly limit hydraulic frac- } \\
\text { turing in Colorado under several hypotheti- } \\
\text { cal conditions?" The battery of conditions in- } \\
\text { cluded six items, such as convincing scientific } \\
\text { evidence showing it is a significant threat to the } \\
\text { environment or public health or a catastrophic } \\
\text { disaster or emergency occurred from oil and } \\
\text { gas development using hydraulic fracturing. } \\
\text { "( } 2) \text { Would you support government decisions } \\
\text { that would significantly expand hydraulic frac- } \\
\text { turing in Colorado under several conditions?" } \\
\text { The battery of hypothetical conditions included } \\
\text { six items, such as scientific evidence showing it } \\
\text { is completely safe to the environment or public } \\
\text { health or regulators passed and enforced stricter } \\
\text { regulations (1= strongly disagree; } 5=\text { strongly } \\
\text { agree). }\end{array}$ & $\begin{array}{l}\text { Averaged values for } \\
\text { the reversed scales } \\
\text { were calculated } \\
\text { for respondents in } \\
\text { favor of hydrau- } \\
\text { lic fracturing for } \\
\text { the limit question, } \\
\text { against hydraulic } \\
\text { fracturing for the } \\
\text { expand question, } \\
\text { and in favor of the } \\
\text { status quo for both. } \\
\text { The resulting un- } \\
\text { willingness to com- } \\
\text { promise measure } \\
\text { ranges from } 1 \text { to } 5 \\
\text { (5= high unwilling- } \\
\text { ness). }\end{array}$ \\
\hline Cognitive Index & $\begin{array}{l}\text { The three dimensions of cognitive conflict com- } \\
\text { bined. }\end{array}$ & $\begin{array}{l}\text { Re-scaled each in- } \\
\text { dividual dimension } \\
\text { (1-3); then mul- } \\
\text { tiplied across the } \\
\text { three dimensions }\end{array}$ \\
\hline $\begin{array}{l}\text { Behavorial } \\
\text { Characteristics }\end{array}$ & Operational Measure & Calculations \\
\hline Behavioral Index & $\begin{array}{l}\text { "Over the past two years have you engaged in } \\
\text { the following activities: mobilizing the public, } \\
\text { providing information to the news media, coun- } \\
\text { tering arguments from opponents, coordinating } \\
\text { with allies, coordinating with opponents, provid- } \\
\text { ing information to government officials, sharing } \\
\text { opinions with government officials and brokering } \\
\text { agreements between parties." }{ }^{\text {a }} \text { Respondents were } \\
\text { coded as } 1 \text { if engaged and } 0 \text { if not engaged. }\end{array}$ & $\begin{array}{l}\text { Added the eight } \\
\text { response items } \\
\text { into an index to } \\
\text { measure the level } \\
\text { of behavioral char- } \\
\text { acteristics for each } \\
\text { respondent }\end{array}$ \\
\hline
\end{tabular}

4 - For this survey question, a component of the question asked respondents how effective these strategies were on a scale of 1-3. This article does not incorporate the measure of perceived effectiveness. 


\begin{tabular}{|l|l|l|}
\hline $\begin{array}{l}\text { Combined } \\
\text { Cognitive and } \\
\text { B e h a v i o r a l } \\
\text { Characteristics }\end{array}$ & Operational Measure & Calculations \\
\hline $\begin{array}{l}\text { Cognitive and } \\
\text { Behavioral Index }\end{array}$ & $\begin{array}{l}\text { The unweighted combination of cognitive and } \\
\text { behavioral }\end{array}$ & $\begin{array}{l}\text { Unweighted each } \\
\text { index and multi- } \\
\text { plied the two }\end{array}$ \\
\hline $\begin{array}{l}\text { Note: See Appendix A, Table A1 for the frequencies of respondents engaging in each of these } \\
\text { activities. Some parts of the question have been paraphrased to fit in this table, see Heikkila } \\
\text { \& Weible (2015) for exact wording. }\end{array}$
\end{tabular}

\section{Source:The Authors}

Index 1: The cognitive index incorporates three characteristics: divergent policy positions, perceived threats, and unwillingness to compromise. In combining these three characteristics into a single index, we created a common scale of $1-3$ for each variable ( $1=$ "low," $2=$ "medium", and $3=$ "high" levels of the conflict characteristic). Values that were one standard deviation below the mean and lower were equal to 1 . Values of one standard deviation above the mean and higher were equal to 3 , and those between one standard deviation below and one standard deviation above were equal to 2 . We then multiplied the scores for each respondent across the characteristics to represent a cognitive conflict index (ranging from 1-27). ${ }^{5}$

Index 2: The index for the behavioral characteristics incorporates eight different political activities, measured dichotomously with 1 if engaged and 0 if not engaged. These eight activities were combined into an additive index to measure the level of behavioral characteristics (ranging from 0 to 8 ).

Index 3: To create a combined index of the cognitive and behavioral characteristics of conflict, we first unweighted the cognitive and behavioral indices to put both on a scale of $0-1$. This involved multiplying each individual score for each index by the maximum value of the index (= respondent's cognitive index score/27 and respondent's behavioral index score/8). Then these two scores were multiplied to create a combined cognitive-behavioral index.

\section{Operationalizing Interpersonal and Intrapersonal Attributes}

This article incorporates several interpersonal and intrapersonal attributes of policy actors to explore the hypothesized relationships between policy actor attributes and conflict characteristics. The intrapersonal attributes include political ideology, as measured by a survey question asking respondents to identify as "extremely liberal," "liberal," "moderate," "conservative", or "extremely conservative" (on a scale of $-2=$ extremely liberal, $+2=$ extremely conservative). In-

5 - These three dimensions form a conflict composite index that combines individual respondents' scores on the three dimensions of the cognitive characteristics of conflict along a concord-conflict spectrum. Unlike typical measures of latent variables, where correlated items in the scale are expected to load on to an abstract concept, we conceptualize the concord-conflict spectrum as being comprised of three dimensions that might or might not be correlated. For example, perceptions of threats might or more not be correlated with divergent policy positions. 
trapersonal attributes include respondents' experience and education. The experience measure came from a question about respondents' level of experience (on a scale of 1 to 4: 1= no experience, $4=$ a lot of experience) of eight activities (i.e., researching technical issues, analyzing financial issues, planning or working on oil and gas operations, regulating, owning mineral rights, living near oil and gas operations, and engaging in political activity to influence government concerning oil and gas). The final variable for the analysis was an additive score of each of the different types of experiences across the eight areas. Education level was measured on a 5-point scale on the survey, from high school degree, some college, bachelor's degree, and master's degree, to $\mathrm{PhD} / \mathrm{MD} / \mathrm{JD}$.

Included under intrapersonal attributes are risk and benefit perceptions. The level of perceived risks relative to perceived benefits was measured using a battery of questions that ranked the level of respondents' agreement with various risks and benefits associated with oil and gas development ( 1 = strongly disagree, $5=$ strongly agree). This measure used the average ranking of the risks for each respondent and subtracted the average ranking of benefits to achieve the measure of perceived "risks relative to benefits". A second indicator was developed for rigidity in perceptions of risks and benefits. This measure came from a survey question that asked respondents whether they had become less concerned, stayed the same, or become more concerned, first about the risks and then about the benefits of oil and gas development $(-1=$ less concerned, $0=$ same, $+1=$ more concerned). These responses were used to calculate rigidity by assigning respondents who want fracking stopped or limited the value of the questions on risks, and respondents who want fracking expanded the value of their response on the benefits. For respondents who had reported wanting oil and gas development to continue at the current rate, we averaged the score of their position on risk and benefit rigidity questions.

Indicators for the interpersonal attributes include network insularity and organizational affiliation. To measure network insularity, we asked respondents to rank the importance of their interactions with various types of groups in achieving their personal or professional goals related to oil and gas development (on a scale of 1 to $5: 1=$ not at all important, $5=$ very important). We used the combined degree of importance of interactions with the two industry groups on the battery, then subtracted the combined score for the interactions with environmental groups and citizen groups, and calculated the absolute value of this measure. A low score is interpreted as "balanced" interactions and a high score equates to more insular interactions. To measure organizational affiliation, we coded the organization types associated with the contact information for the respondent. In this analysis, respondents are associated with three groups: 1 ) private industry or industry association; 2) environmental organizations or citizens' groups; and 3) government organizations or others. Government/other affiliations are the baseline group in the models that follow.

\section{Results}

\section{Describing the Cognitive and Behavioral Characteristics of Policy Conflict}

The summary statistics for both the cognitive and behavioral characteristics of conflict indicate that the policy actors in the oil and gas subsystem in Colorado fall on a spectrum of conflict. The distribution of scores on the three dimensions of cognitive characteristics varies widely across the survey sample. The average scores on the individual dimensions of cognitive characteristics are skewed toward the higher end of the scales, but with wide variance in responses and with the mean scores falling just above the mid-range of the scales. (See Appendix A, Table A1 for the descriptive statistics on these variables). The distribution of the composite cognitive index 
is similar. The mean score on a scale of $1-27$ is 9.48 , but there is wide variance in the scores (s.d.=7.17). As we have previously shown, the distribution is slightly skewed toward moderate to higher levels of conflict intensity, or to scores above the median, which is the multiplicative moderate value for the three dimensions (Heikkila \& Weible, 2017).

The behavioral characteristics show similar patterns. First, in the behavioral index, the mean score is 5.89 on a scale of $0-8$, suggesting a positively skewed distribution. Yet there is wide variance again among respondents, with a standard deviation of 2.32. (See Appendix A, Table 2). Still, a large proportion of the policy actors in this population $(60 \%-90 \%)$ is engaged in each of the behavioral activities comprising the composite behavioral index. Given that the definition of policy actors includes people who are somehow actively involved in trying to shape a policy outcome, and thus the nature of the sampling frame, it is not surprising that a large proportion of actors engage in these behavioral activities.

When looking at the combined index of cognitive and behavioral conflict characteristics (calculated by multiplying the unweighted cognitive score and unweighted behavioral score), we find some notable patterns. Figure 1 below presents a density distribution in a sunflower plot of both the unweighted indices together. Each of the shorter lines on the plot represents one respondent, a longer line represents two respondents, the point where two lines cross represents four respondents and additional lines are added to the "sunflowers" for each additional respondent. Not surprisingly, policy actors, who tend to score higher on the cognitive index, also score higher on the behavioral index. However, many policy actors show higher levels on the behavioral index but have lower to moderate scores on the cognitive index. This may be because there is a large proportion of respondents that is not affiliated with interest groups. Some $54 \%$ of the respondents affiliate with government or research/media/consulting. It is quite possible that many policy actors engage in behaviors to influence public policy but do not perceive or feel the same level of intensity of conflict cognitively as do other policy actors.

Figure 1. Density-Distribution Sunflower Plot for Conflict Composite and Behavioral Composite Indexes

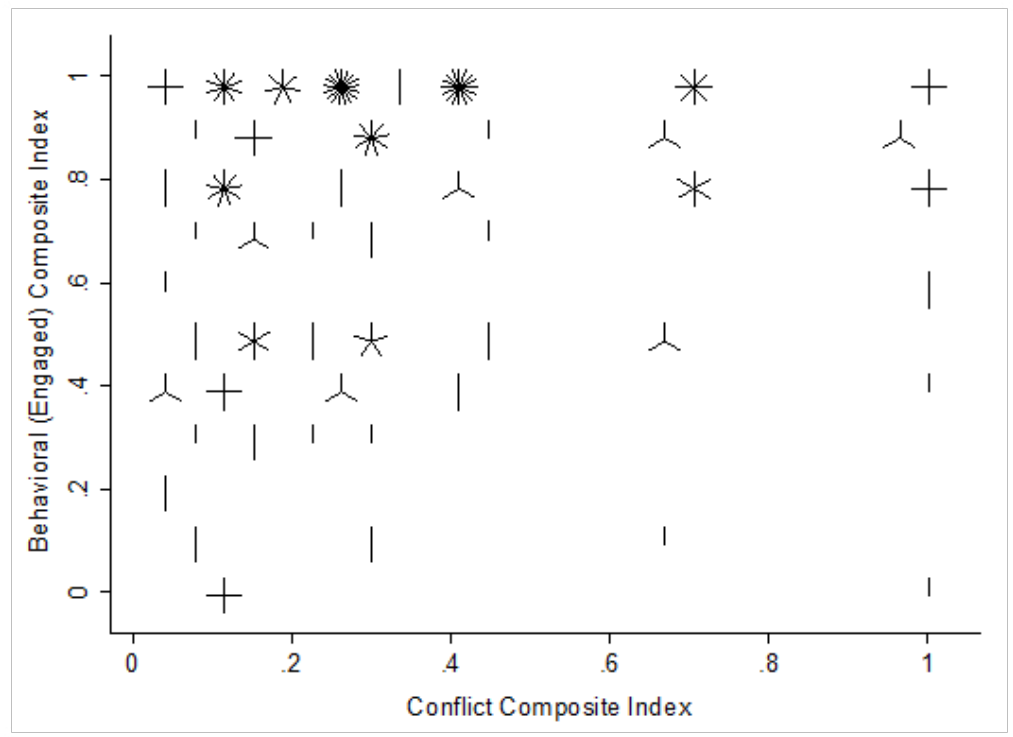

Source: The Authors 


\section{Exploring How Policy Actor Attributes Relate to Conflict Characteristics}

The second aim of this study was to examine how policy actor attributes related to conflict characteristics. Previous research emphasized that rigidity of risk-benefit perceptions, insular networks, and affiliations with advocacy groups (industry and environmental organizations in this context) were associated with the individual dimensions of cognitive characteristics and the combined index (Heikkila \& Weible, 2017). In this article, we explore these policy actor attributes in relation to the behavioral characteristics index, and in relation to the combined cognitive-behavioral index. Also, unlike this previous analysis of the cognitive characteristics, we examine how the behavioral characteristics help explain cognitive characteristics and viceversa.

Table 2 summarizes the results of three ordered logit models using each of the three indices (cognitive, behavioral, and combined cognitive-behavioral) as dependent variables. The independent variables are the intrapersonal and interpersonal actor attributes. For the cognitive model, we include the behavioral index as an explanatory variable and, for the behavioral model, we include the cognitive index as an explanatory variable.

Table 2. Ordered Logit Models for Cognitive, Behavioral and Combined Indexes

\begin{tabular}{|c|c|c|c|}
\hline & $\begin{array}{l}\text { Cognitive } \\
\text { Composite Index }\end{array}$ & $\begin{array}{l}\text { Behavioral } \\
\text { Composite Index }\end{array}$ & $\begin{array}{l}\text { Cognitive \& } \\
\text { Behavioral } \\
\text { Composite Index }\end{array}$ \\
\hline & Odds Ratio (s.e.) & Odds Ratio (s.e.) & Odds Ratio (s.e.) \\
\hline Intrapersonal Attributes & $0.69^{*}$ & 1.03 & 0.74 \\
\hline Political Ideology & $(0.16)$ & $(0.25)$ & $(0.17)$ \\
\hline Experience & $\begin{array}{l}0.96 \\
(0.04)\end{array}$ & $\begin{array}{l}1.25^{* * *} \\
(0.05)\end{array}$ & $\begin{array}{l}1.10^{* *} \\
(0.04)\end{array}$ \\
\hline Education & $\begin{array}{l}0.89 \\
(0.14)\end{array}$ & $\begin{array}{l}1.22 \\
(0.20)\end{array}$ & $\begin{array}{l}1.03 \\
(0.16)\end{array}$ \\
\hline Risk-Benefit Perceptions & $\begin{array}{l}1.06 \\
(0.12)\end{array}$ & $\begin{array}{l}0.98 \\
(0.11)\end{array}$ & $\begin{array}{l}1.02 \\
(0.11)\end{array}$ \\
\hline Risk-Benefit Rigidity & $\begin{array}{l}3.02^{* * *} \\
(0.89)\end{array}$ & $\begin{array}{l}1.42 \\
(0.43)\end{array}$ & $\begin{array}{l}3.16^{* * *} \\
(0.90)\end{array}$ \\
\hline
\end{tabular}




\begin{tabular}{|c|c|c|c|}
\hline $\begin{array}{l}\text { Interpersonal Attributes } \\
\text { Insular Networks }\end{array}$ & $\begin{array}{l}1.39^{* * *} \\
(0.11)\end{array}$ & $\begin{array}{l}0.94 \\
(0.08)\end{array}$ & $\begin{array}{l}1.28^{* *} \\
(0.10)\end{array}$ \\
\hline Oil \& Gas Industry Affiliation & $\begin{array}{l}3.23^{* *} \\
(1.36)\end{array}$ & $\begin{array}{l}0.85 \\
(0.37)\end{array}$ & $\begin{array}{l}2.39^{* *} \\
(0.98)\end{array}$ \\
\hline $\begin{array}{l}\text { Env. or Citizen Group Affili- } \\
\text { ation }\end{array}$ & $\begin{array}{l}1.53 \\
(0.69)\end{array}$ & $\begin{array}{l}3.18^{* *} \\
(1.56)\end{array}$ & $\begin{array}{l}3.51^{* *} \\
(1.51)\end{array}$ \\
\hline Cognitive Composite Index & -- & $\begin{array}{l}1.02 \\
(0.03)\end{array}$ & --- \\
\hline Behavioral Composite Index & $\begin{array}{l}1.19^{* *} \\
(0.09)\end{array}$ & --- & --- \\
\hline Number of Observations & 171 & 171 & 171 \\
\hline Likelihood Ratio $\mathrm{Chi}^{2}$ & 73.73 & 53.38 & 75.41 \\
\hline P-Value & 0.000 & 0.000 & 0.000 \\
\hline Pseudo $\mathrm{R}^{2}$ & 0.11 & 0.08 & 0.07 \\
\hline
\end{tabular}

Notes: All coefficients are odd ratios from Ordered Logit Models. $\mathrm{p}<0.10^{*}, \mathrm{p}<0.05^{* *}$, $\mathrm{p}<0.001^{* * *}$

\section{Source: The Authors}

The results for the cognitive index model are similar to previous findings (Heikkila \& Weible, 2017), except that, by adding the behavioral index to the model (which is positive and significant), the environmental organizational affiliation variable is no longer significant. This may be because many of the policy actors who exhibit high scores on the behavioral index are associated with environmental organizations, which would then dampen the effect of the environmental organization affiliation in relation to government/other (the baseline organizational affiliation) in the model. Still, the variable for oil and gas industry affiliation is significant and positive in the cognitive model. In other words, relative to government/other affiliations, the odds of policy actors perceiving cognitive conflict characteristics are higher when actors are affiliated with industry. More conservative political affiliations (positive on the ideology scale) have slightly lower odds of being higher on the cognitive conflict index, but rigid risk and benefit perceptions and insular networks lead to greater odds of scoring high on the cognitive index. 
The results for the behavioral model present a slightly different story than do the cognitive characteristics. In this model, more experience with oil and gas issues is associated with higher odds of engaging in conflict behaviors. This supports the second hypothesis, based on the assumption that these types of behaviors require resources, time, and often knowledge which may come with more experience. The only other policy actor attribute significantly related to the behavioral index is environmental affiliation. Relative to government/other affiliations, the odds of engaging in conflict behaviors go up with environmental organizational affiliations. This pattern reinforces an interpretation of the results for the behavioral and environmental affiliation variables discussed above in the cognitive model. In other words, in this policy context, environmental organizations may be engaging more in these types of behaviors (or at least self-reporting that they engage more frequently). However, notably, the cognitive characteristics of conflict do not affect the odds of engaging in more of the behavioral characteristics of conflict, which we did not expect.

For the combined conflict index, the results reflect the findings in the other two models. In other words, we see higher levels of experience, rigid risk-benefit perceptions, and affiliations with industry and environmental organizations as being significant and associated with greater odds of scoring high on conflict characteristics. All these findings lend support to the hypotheses. At the same time, we recognize that the nuanced differences between the findings for the behavioral and cognitive index may highlight the need for refinement and re-evaluation of some of the hypotheses in relation to cognitive versus behavioral characteristics.

\section{Conclusion}

The concept of policy conflict has been conceptually and theoretically neglected in the study of policy and politics. This article contributes knowledge about the characteristics of policy conflicts with insights drawn from policy actors involved in oil and gas politics in Colorado. The analysis described the characteristics of policy conflict and then explained variation in these characteristics, in part, with intrapersonal and interpersonal attributes of policy actors.

As prior research showed (Heikkila \& Weible, 2017), policy actors lie on a spectrum in their cognitive characteristics of conflict. This spectrum spans policy actors who perceive high policy conflict and those who perceive high policy concord. For what has been an ostensibly contentious issue of oil and gas development in Colorado, this reveals that perceptions of conflict are not ubiquitous across a population.

Enriching the interpretations of the cognitive characteristics of conflict are the behavioral characteristics. The result shows that most policy actors engage in some political behavior, which is not unexpected given that the target population of the survey was policy actors. Additionally, policy actors, whose perception spans the spectrum of the cognitive characteristics of conflict, engage in various political behaviors. Those who engage in political behaviors perceive both low and high cognitive characteristics of conflict.

We then find that the dual characteristics of conflict tend to be explained by experience, rigidity in risk and benefit perceptions, insular networks, and different organizational affiliations, which corroborate the third, fourth, and fifth hypotheses. Yet the results differ between the cognitive and behavioral indices when modeled separately. For instance, ideology and industry affiliation are significant in the cognitive model but not in the behavioral; whereas experience and environmental affiliations are significant in the behavioral model but not in the cognitive. Additionally, the behavioral characteristics explain some of the dimensions of the cognitive characteristics of conflict, but the reverse is not confirmed; in other words, the cog- 
nitive characteristics of conflict do not affect the odds of engaging in more of the behavioral characteristics of conflict. Again, we did not have specific hypotheses about how the cognitive and behavioral characteristics relate to one another, but, in this case at least, we find that behaviors may be more likely to drive cognitive characteristics than the reverse. In other words, our hypotheses - and our knowledge about policy conflicts - may need to be refined to capture these differences in the cognitive and behavioral characteristics. We also need to pay attention to whether these characteristics, and their underlying dimensions explored in this study, are of theoretical importance for the question and the case at hand.

These findings have several theoretical implications, which we organize under the PCF and the broader study of policy conflict. We phrase these implications as questions to guide future research agendas on policy conflicts. First, what is the relationship between the cognitive and behavioral characteristics of conflict? Many theoretical models of behavior depict thoughts preceding action (e.g., Stern, 2000; Ajzen, 1991; Jenkins-Smith et al., 2014) and others, such as the PCF, are more ambiguous. However, the empirical results herein suggest that behaviors precede action. The relationship between cognitive and behavioral characteristics could be endogenous with one shaping and being shaped by the other. Alternatively, the patterns discovered might reflect the idiosyncratic tendencies in the case study and the measurements. Then again, the relationship between the cognitive and the behavioral characteristics of conflict might somehow depend on time, including how long the policy conflict has been recognized and the nature of its development. In older policy conflicts, compared with more nascent ones, the cognitive characteristics of conflict could, arguably, be more likely to be affected by past political behaviors. Moreover, this article is unable to unravel completely how the cognitive and the behavioral characteristics of policy conflict actually interact and evolve over time, which could be explored in a number of ways including in-depth interviews. Thus, the data used in this article prevent the complete untangling of this relationship, but prompt more research in this area.

Second, what are the theoretical and methodological implications of analyzing policy conflicts as individual and collective phenomena? Policy conflicts emerge within individuals, but also in aggregation at different levels of analysis, such as a policy action situation, a policy subsystem, or a political system (Weible \& Heikkila, 2017). The experience of individuals will likely vary within a population on any given policy issue with some experiencing low-intensity policy conflict (or high policy concord) and others experiencing high-intensity policy conflict. When these individual measures are combined and, thus, form a distribution of conflict intensity within a population, the causes and effects of such distributions are unknown. Among the next steps is to explore policy conflicts at different levels and to compare these conflicts, both within and across different policy settings, to ascertain the multifaceted nature of this phenomenon.

Third, how generalizable are findings on oil and gas conflicts in Colorado in terms of other policy subsystems or other policy issues? Despite the importance of conflict in policy and politics, any argument about the generalizability of the findings from this analysis is speculation. There has simply not been enough focus on policy conflicts through in-depth or comparative case studies to assess the generalizability of the findings. Until this happens, any capacity to interpret the characteristics of conflict from a larger perspective remains handicapped.

Fourth, what are the trade-offs in using different research methods to capture the characteristics of the policy conflict concept? The policy-conflict concept consists of two characteristics, each with a number of dimensions (Weible \& Heikkila, 2017). The empirical data herein were collected from an online survey of policy actors. Such a method of data collection can be unfeasible in some settings and unaffordable in others. Similarly, comparative research agendas often re- 
quire the use of interviews, coding procedures, or different forms of data collection other than online surveys, and for some of these data sources precise measures of policy conflict become unrealistic. Thus, some data sources allow researchers to measure these characteristics and dimensions directly. For other data sources, the underlying dimensions of conflict characteristics may be difficult to measure directly, resulting in an emphasis on particular aspects of the concept over others, or in more blunt measures. As with any data source, the trade-offs should be considered. For instance, less complete measures of cognitive conflict characteristics might be found in news-media data, but an advantage of such data would be an enhanced capacity to study characteristics longitudinally. Another consideration in measuring policy conflict characteristics is how to model some of their underlying dimensions in ways that are theoretically relevant for a given context. For example, one could weigh different measures of the behavioral characteristics of policy conflict by their cooperative or adversarial traits. Moving forward in the study of policy conflict necessitates some research efforts that disaggregate the concept into constitutive dimensions, and other studies which may retain more aggregated measures, or which measure only a few of the dimensions. Among the next steps in the study of policy conflict is the devising of strategies for measuring and modeling the concepts with different data sources and recognizing the strengths and limitations of different approaches. Accepting the necessity of different measures of policy conflict, a shared conceptual understanding of such conflict becomes obligatory in binding various research efforts together.

Fifth, to what extent does policy conflict, as a concept, relate to other theoretical approaches to politics and policy? The intersection of policy conflict with other approaches in studying policy and politics is necessary. For example, the data collected in this article could be used to identify two rival coalitions, as guided by the Advocacy Coalition Framework (ACF) (Heikkila and Weible, 2016). On one side of the debate would be a pro-fracking coalition consisting of industry and some local and state government officials. On the other side would be an anti-fracking coalition, consisting of environmental and citizens' groups, many scientists, and some government officials from local, state, and federal levels. However, the identification of coalitions is not tantamount to claims of low, moderate, or high levels of conflict. Indeed, the evidence in this article suggests that not everyone perceives conflict, yet there are likely to be two coalitions operating in this issue area. Among the unanswered questions to explore is the relationship between advocacy coalitions and the intensity of the cognitive and behavioral characteristics of policy conflict.

Questions remain about the nature of policy conflicts. Policy conflicts are complex and the distribution of conflict characteristics across actors, and the sources of those characteristics, will undoubtedly vary across different policy issues and settings. The primary contribution of this article is not a solidified, generalizable answer to all policy conflicts, but the attention that this article brings to policy conflict to help build knowledge about these phenomena. The hope is to motivate others to analyze policy conflicts in different settings and to explore their intricacies. Only through a concerted effort by many scholars, over time and across issues, can we learn about the meaning of policy conflicts in any given setting, draw generalizable lessons and help to advance the knowledge about policy and politics.

\section{Bibliography}

Ajzen, I. (1991). The Theory of Planned Behavior. Organizational Behavior and Human Decision Processes, 50(2), 179-211 
Baumgartner, F.R., \& Jones, B.D. (1993). Agendas and Instability in American Politics. Chicago, IL: University of Chicago Press.

Baumgartner, F.R., Berry, J.M, Hojnacki, M., Kimball, D.C, \& Leach, B.L. (2009). Lobbying and Policy Change. Chicago, IL: The University of Chicago Press.

Billig, M. G., \&Tajfe, H. (1973). Social Categorization and Similarity in Intergroup Behavior. European Journal of Social Psychology, 3(1), 27-52.

Cobb, R. W.,\& Elder, C.D. (1972). Participation in American Politics: The Dynamics of Agenda-Building. Baltimore, MD: The John Hopkins University Press.

Heikkila, T. \& Weible, C.M. (2015). A Summary Report of a 2015 Survey of the Politics of Oil and Gas Development that Uses Hydraulic Fracturing in Colorado. Published July 24, 2015 by the School of Public Affairs University of Colorado Denver.

Heikkila, T., \& Weible, C.M. (2016). Contours of Coalition Politics in the United States." In C.M. Weible, T.Heikkila, K. Ingold, \& M. Fischer (Eds.), Policy Debates on Hydraulic Fracturing: Comparing Coalition Politics in North America and Europe (pp. 29-52). New York, NY: Palgrave Macmillan.

Heikkila, T., \& Weible, C.M. (2017). Unpacking the Intensity of Policy Conflict: A Study of Colorado's Oil and Gas Subsystem. Policy Sciences, 50(2), 179-193.

https://doi.org/10.1007/s11077-017-9285-1

Heikkila, T., Weible, C.M, \& Olofsson; K. (2017). Lessons from State-Level and National-Level Policy Conflicts over U.S. Shale Development. Environment: Science and Policy for Sustainable Development, 59(3), 4-13.

Hood, G. (2016). Fight over Drilling Could Spill onto November ballots. March 9, 2016. Colorado Public Radio. Retrieved from:

https://www.cpr.org/2016/03/09/greeley-fight-over-drilling-could-spill-to-novembers-ballots Jenkins-Smith, H.C. (1990). Democratic Politics and Policy Analysis. Pacific Grove, CA: Brooks/Cole.

Jenkins-Smith, H., Nohrstedt, D., \& Sabatier, P.A. (2014). The Advocacy Coalition Framework: Foundations, Evolution, and Ongoing Research. In P.A. Sabatier (Ed.), Theories of the Policy Process. (3rd ed., pp. 183-224). Boulder, CO: Westview Press.

Kahan, D.M. (2012). Ideology, motivated reasoning, and cognitive reflection: An experimental study. Judgment and Decision Making, 8, 407-424.

Kahneman, D. \& Tversky, A. (2013). Prospect Theory: An Analysis of Decision under Risk, Econometrica, 47(2), 263-291.

Lasswell, H.D. (1971). A Preview of Policy Sciences. New York, NY: American Elsevier Publishing Company.

Ostrom, E. (2009). Understanding Institutional Diversity. Princeton, NJ: Princeton University Press.

Pralle, S.B. (2006). Branching out Digging in. Washington, DC: Georgetown University Press.

Schattschneider, E. E. (1957). Intensity, visibility, direction and scope. The American Political Science Review, 51(4), 933-942.

Schattschneider, E. E. (1960). The Semisovereign People: A Realist's View of Democracy in America (Illinois.Stern, P.C. (2000). Towards a Coherent Theory of Environmentally Significant Behavior. Journal of Social Issues, 56(3), 407-424.

Susskind, L., McKearnan, S., \& Thomas-Larmer; J. (Eds.) (1999). The Consensus Building Handbook: A Comprehensive Guide to Reaching Agreement. Thousand Oaks, CA: Sage Publications. 
Tajfel, H., Billig, M.G., Bundy, R.P., \& Flament, C. (1971). Social Categorization and Intergroup Behavior. European Journal of Social Psychology, 1(2), 149-78.

Tilly, C., \& Tarrow, S. (2007). Contentious Politics. New York, NY: Oxford University Press.

U.S.EnergyInformationAdministration.(2014a).ColoradoStateProfileandEnergyAnalysis.U.S.Energy Information Administration, Washington, DC. Retrieved from:

http://www.eia.gov/state/analysis.cfm?sid=CO

U.S. Energy Information Administration. (2014b). Natural Gas Gross Withdrawals and Production. U.S. Energy Information Administration, Washington, DC. Retrieved from:

http://www.eia.gov/dnav/ng/ng_prod_sum_dcu_NUS_m.htm

Weible, C.M. (2008). Expert-Based Information and Policy Subsystems: A Review and Synthesis. Policy Studies Journal, 36(4), 615-635.

Weible, C.M. \& Heikkila, T. (2016). Comparing the Politics of Hydraulic Fracturing in New York, Colorado, and Texas. Review of Policy Research, 33(3), 232-250.

Weible, C.M. \& Heikkila, T. (2017). Policy Conflict Framework. Policy Sciences, 50(1), 23-40.

\section{Appendix}

Table A1. Frequencies of Engagement in Reported Political Behaviors

\begin{tabular}{|l|l|l|}
\hline & $\begin{array}{l}\text { N (Percent) } \\
\text { Engaged }\end{array}$ & $\begin{array}{l}\text { N (Percent) } \\
\text { Not Engaged }\end{array}$ \\
\hline Mobilizing the Public & $115(61 \%)$ & $74(39 \%)$ \\
\hline Providing Information to Government & $157(83.5 \%)$ & $31(16.5 \%)$ \\
\hline $\begin{array}{l}\text { Providing Information to Media } \\
\text { Sharing Opinion with Government }\end{array}$ & $131(70 \%)$ & $57(30 \%)$ \\
\hline $\begin{array}{l}\text { Brokering Agreements } \\
\text { Countering Arguments of People You Disagree } \\
\text { With }\end{array}$ & $168(90 \%)$ & $33(17.5 \%)$ \\
\hline $\begin{array}{l}\text { Collaborating with Opponents } \\
\text { Coordinating with Allies }\end{array}$ & $119(63 \%)$ & $69(37 \%)$ \\
\hline
\end{tabular}


Table A2. Descriptive Statistics of Model Variables

\begin{tabular}{|c|c|c|c|c|c|}
\hline Dependent Variables & $\begin{array}{l}\text { Valid } \\
\text { Cases }\end{array}$ & Minimum & Maximum & Mean & $\begin{array}{l}\text { Std. } \\
\text { Deviation }\end{array}$ \\
\hline Divergent Policy Position & 196 & .04 & 2.04 & .96 & .75 \\
\hline Perceived Threats & 205 & 2.00 & 10.00 & 6.83 & 2.25 \\
\hline Unwilling to Compromise & 188 & 1.40 & 5.00 & 3.29 & .81 \\
\hline Cognitive Composite Index & 186 & 1.00 & 27.00 & 9.48 & 7.17 \\
\hline Behavioral Index & 183 & 0.00 & 8.00 & 5.89 & 2.32 \\
\hline $\begin{array}{l}\text { Combined Cognitive-Behavioral } \\
\text { Index }\end{array}$ & 176 & 0.00 & 1.00 & 0.28 & 0.24 \\
\hline Scaled Explanatory Variables & $\begin{array}{l}\text { Valid } \\
\text { Cases }\end{array}$ & Minimum & Maximum & Mean & $\begin{array}{l}\text { Std. } \\
\text { Deviation }\end{array}$ \\
\hline $\begin{array}{l}\text { Political View }(-2=\text { extremely } \\
\text { liberal; }+2=\text { extremely } \\
\text { conservative })\end{array}$ & 186 & -2 & 2 & -.25 & .83 \\
\hline Diversity of Experience & 190 & 8.00 & 32.00 & 20.62 & 4.66 \\
\hline Level of Education & 189 & 2.00 & 6.00 & 4.93 & .93 \\
\hline $\begin{array}{l}\text { Perceived Risks Relative to } \\
\text { Benefits }\end{array}$ & 213 & -4.00 & 4.00 & -.31 & 2.10 \\
\hline $\begin{array}{l}\text { Rigidity of Risks and } \\
\text { Benefits }\end{array}$ & 207 & -1.00 & 1.00 & .55 & .52 \\
\hline Insular Networks & 192 & 0.00 & 8.00 & 2.20 & 2.01 \\
\hline Dummy Explanatory Variables & $\begin{array}{l}\text { Valid } \\
\text { Cases }\end{array}$ & $\mathrm{N}$ & $\%$ & & \\
\hline Industry Affiliation & 236 & 64 & 27 & & \\
\hline $\begin{array}{l}\text { Env. or Citizen Group } \\
\text { Affiliation }\end{array}$ & 236 & 44 & 18 & & \\
\hline Government or Other Affiliation & 236 & 128 & 54 & & \\
\hline
\end{tabular}

